13

\title{
Десорбция положительных ионов металла с поверхности массивного анода на пластину цеолита
}

\author{
() В.И. Орбух, ${ }^{1}$ Н.Н. Лебедев, ${ }^{1}$ З.А. Агамалиев, ${ }^{1}$ Г.М. Эйвазова, ${ }^{2}$ Б.Г. Саламов ${ }^{3}$ \\ ${ }^{1}$ Институт ффизических проблем Бакинского государственного университета, \\ AZ1148 Баку, Азербайджан \\ ${ }^{2}$ НАНО-центр, Бакинский государственный университет, \\ AZ1148 Баку, Азербайджан \\ ${ }^{3}$ Институт фризики НАН Азербайджана, \\ AZ1143 Баку, Азербайджан \\ e-mail: nnlebedeva@gmail.com
}

Поступило в Редакцию 20 декабря 2018 г.

В окончательной редакции 5 июня 2019 г.

Принято к публикации 12 сентября 2019 г.

Рассмотрено явление переноса положительных ионов металла с поверхности массивного анода на поверхность цеолитовой пластины в аномально малом для этого явления внешнем электрическом поле. Объяснение наблюдаемого явления основано на том, что в электрическом поле на проводящих порах цеолита вблизи анода возникает отрицательный заряд, локализованный на стенках пор, создающий аномально большое локальное электрическое поле на поверхности анода. Это поле осуществляет перенос ионов с анода на поверхность цеолита. Приведены соображения, объясняющие пороговый (по величине внешнего поля) характер явления.

Ключевые слова: цеолит, ионный обмен, ионы серебра, массоперенос.

DOI: $10.21883 /$ JTF.2020.02.48828.2607

\section{Введение}

Явление массопереноса широко обсуждается в литературе, так как перенос массы сопровождает различные физические явления, такие как электросварка, электрополевая модификация нанокомпозитов [1], полевая десорбционная микроскопия [2]. Массоперенос наблюдается также в пористых телах с жестким каркасом [3], при исследовании механических свойств кристаллов при наноидентировании [4], на контакте химически неоднородных минералов [5].

В настоящей работе представлен массоперенос ионов с поверхности массивного металлического электрода анода - на поверхность механически прижатой к нему пластины цеолита-клиноптилолита.

В работах [6-9] рассматривается поверхностная ионизация, в результате которой на поверхностях тел образуются положительные и отрицательные ионы при испарении с них атомов и молекул. В монографии [10] впервые были систематизированы результаты экспериментальных исследований поверхностной ионизации и даны основные теоретические представления. В [11] рассмотрены результаты исследования поверхностной ионизации атомов щелочных металлов и органических молекул на поверхности интерметаллида золота, существенно расширяющие представления о явлении. Как видно из обзора приведенных работ, ионизация требует разогрева поверхности. Однако есть возможность массопереноса ионов с ненагреваемой поверхности металла под действием сильных $\left(10^{8} \mathrm{~V} / \mathrm{cm}\right)$ электрических полей [12-16].
Сильные электрические поля стали доступными для количественной работы в результате использования иглообразных автоэлектронных эмиттеров, это привело к открытию нового эффекта - десорбции электрическим полем. Полевая десорбция - это эмиссия ионов под действием электрического поля. Теоретические оценки напряженности поля десорбции для различных металлов находятся в интервале $1428-288 \mathrm{MV} / \mathrm{cm}$.

В нашем случае вышеперечисленные условия не реализуются. В настоящей работе наблюдается массоперенос ионов металла с ненагреваемой поверхности массивного анода на поверхность прижатой к нему цеолитовой пластины при приложении достаточно слабого $(U=50 \mathrm{~V})$ постоянного электрического поля. Полагаем, что это возможно благодаря свойствам цеолита.

Цеолиты являются водными алюмосиликатами, бесконечный алюмосиликатный каркас которых образуется при сочленении через общие вершины тетраэдров $\left[\mathrm{SiO}_{4}\right]^{4-}$ и $\left[\mathrm{AlO}_{4}\right]^{5-}$, имеющих сообщающиеся между собой полости, занятые большими ионами и молекулами воды [17]. Слабосвязанные катионы и молекулы воды в порах цеолитов характеризуются значительной подвижностью, что обеспечивает возможность ионного обмена и обратимости дегидратации без влияния на алюмосиликатный жесткий каркас. Благодаря этому свойству цеолиты имеют необычайно широкую сферу использования в промышленности и сельском хозяйстве.

В настоящее время известны более 45 видов природных цеолитов, из которых наиболее распространенными являются клиноптилолит, гейландит, филлипсит, 
ломонит, морденит, эрионит, шабазит, феррьерит, анальцим. Клиноптилолит определяется как серия цеолитовых минералов, имеющих четкую структурную топологию гейландита $(\mathrm{HEU})$ и соотношение $\mathrm{Si} / \mathrm{Al}>4.0$.

Структурная топология тетраэдрической HEU-решетки достаточно исследована и имеет $C 2 / m$ симметрию со сплющенными каналами, ограниченными десятичленными $(7.5 \times 3.1 \AA)$ и восьмичленными тетраэдрическими кольцами $(4.6 \times 3.6 \AA)$, параллельными оси $C$. Добавочные восьмичленные кольцевые каналы $(4.7 \times 2.8 \AA)$ параллельны [100] и [102] и пересекаются с предшествующими каналами в пределах [010], образуя систему из двумерных параллельных каналов к [010], которые ответственны за слоистую структуру $[17,18]$.

Анализ данных по структуре и свойствам позволяет рассматривать этот цеолит не только как перспективный сорбент, но и как объект, на котором можно исследовать пороэмиссию электронов, размножение электронов и газовый разряд в порах [19], диэлектрические и электрические свойства [20]. Если сорбционные свойства цеолита определяются размерами и конфигурацией пор, то его электрические свойства определяются составом вещества в поровом пространстве [21]. На основе рентгенографического и спектрального химического анализа установлена принадлежность исследуемого природного цеолита к высококремнеземным цеолитам типа клиноптилолит [22]. Содержимое каналов представляет собой внекаркасную подсистему - это положительно заряженные ионы-катионы $\mathrm{Na}^{+}, \mathrm{K}^{+}, \mathrm{Mg}^{+}, \mathrm{Ca}^{+}$, компенсирующие отрицательный заряд каркаса, а также большое количество молекул $\mathrm{H}_{2} \mathrm{O}$-координационной воды. Вода играет важную роль для обеспечения стабильности каркаса клиноптилолита и, как полагают [23], приводит к увеличению подвижности ионов в поровом пространстве. Слабосвязанные катионы и молекулы воды в порах цеолитов приводят к большим значениям диэлектрической проницаемости на низких частотах и существенной зависимости электрофизических свойств цеолитов от частоты и температуры. Способность катионов диффундировать сквозь большую открытую цеолитовую структуру дает возможность получения высокой ионной проводимости в цеолитах. За последние годы сделано немало попыток исследования факторов, которые управляют ионным транспортом во внешнем электрическом поле [24]. Эти исследования сфокусированы главным образом на влиянии температуры, степени гидратации, природы металлических катионов на проводимость, измеряемую на переменном напряжении.

Наблюдаемый в настоящей работе перенос вещества анода на поверхность цеолитовой пластины объясняется образованием неподвижного отрицательного заряда, сосредоточенного на хаотически ориентированных кристаллитах цеолита. Перенос массы электрода осуществляется в тех малых участках поверхности цеолита, где электрическое поле велико.

\section{Измерения}

В качестве объекта исследования был использован природный цеолит клиноптилолит: сингония - моноклинная, пространственная группа симметрии $C 2 / m$; параметры элементарной ячейки: $a=1.761, b=1.780$, $c=0.741 \mathrm{~nm}, \beta=115.2^{\circ}$. Для эксперимента из объемного моноблока природного цеолита клиноптилолита, химический состав которого, подтвержденный проведенным рентгенографическим анализом, содержал $\mathrm{Al}_{2} \mathrm{O}_{3}-$ 11.36, $\mathrm{SiO}_{2}-67.84, \mathrm{Na}_{2} \mathrm{O}-1.25, \mathrm{MgO}-0.49, \mathrm{P}_{2} \mathrm{O}_{5}-$ $0.11, \mathrm{SO}_{3}-0.03, \mathrm{~K}_{2} \mathrm{O}-3.01, \mathrm{CaO}-0.29, \mathrm{TiO}_{2}-0.08$, $\mathrm{MnO}-0.078, \mathrm{Fe}_{2} \mathrm{O}_{3}-1.19, \mathrm{KJ}-11.64$, нарезались пластины размером $15 \times 10 \times 2 \mathrm{~mm}$.

Для введения ионов серебра в поры, пластина цеолита подвергалась ионному обмену в растворе $0.02 \mathrm{M} \mathrm{AgNO}_{3}$, что было зарегистрировано элементным составом, изучаемым методом сканирующей (SEM) электронной микроскопии на приборе FE JEOL JSM7600F. На рис. 1 представлены суммарный спектр карты до $(a)$ и после $(b)$ введения серебра, где видно, как Ag замещает Са в порах цеолита.

Такая модифицированная пластина помещалась в кассету, где была зажата между двумя плоскими отполированными дисками-электродами из меди и нержавеющей стали марки AISI 304. Это сложнолегированный сплав, в составе которого содержатся такие элементы, как хром $(18-20 \%)$, никель $(8-11 \%)$. Электрод из нержавеющей стали был анодом. На электроды подавалось постоянное напряжение $50 \mathrm{~V}$. Как было показано в [25], ток со временем медленно возрастал и через $20 \mathrm{~h}$ выходил на стационарное значение $3 \cdot 10^{-4} \mathrm{~A}$.

В результате прохождения тока положительные ионы серебра накапливаются у торца пластины, обращенной к медному электроду-катоду.

На противоположном торце пластины, обращенном к аноду из нержавеющей стали, формируется отрицательный заряд. Оказалось, что в результате длительного $(20 \mathrm{~h})$ прохождения малого по величине $\left(10^{-4} \mathrm{~A}\right)$ тока, на поверхность цеолитовой пластины перешли ионы с анода. На рис. 2 показана фотография обращенной к аноду поверхности цеолитовой пластины, модифицированной серебром, после прохождения тока.

На рис. 3 представлен суммарный спектр карты на площади поверхности цеолита с ионами из анода.

Сравнение рис. 1 и 3 показывает, что из анода на цеолит перешли ионы железа и хрома, которые содержит нержавеющая сталь. Как видно, перенос ионов из анода идет не по всей площади контакта, а на локальных участках. Отметим, что интенсивность переноса существенно зависит от времени выдержки в поле.

\section{Обсуждение результатов}

Наблюдаемый экспериментально массоперенос мы объясняем ионной полевой эмиссией с поверхности 

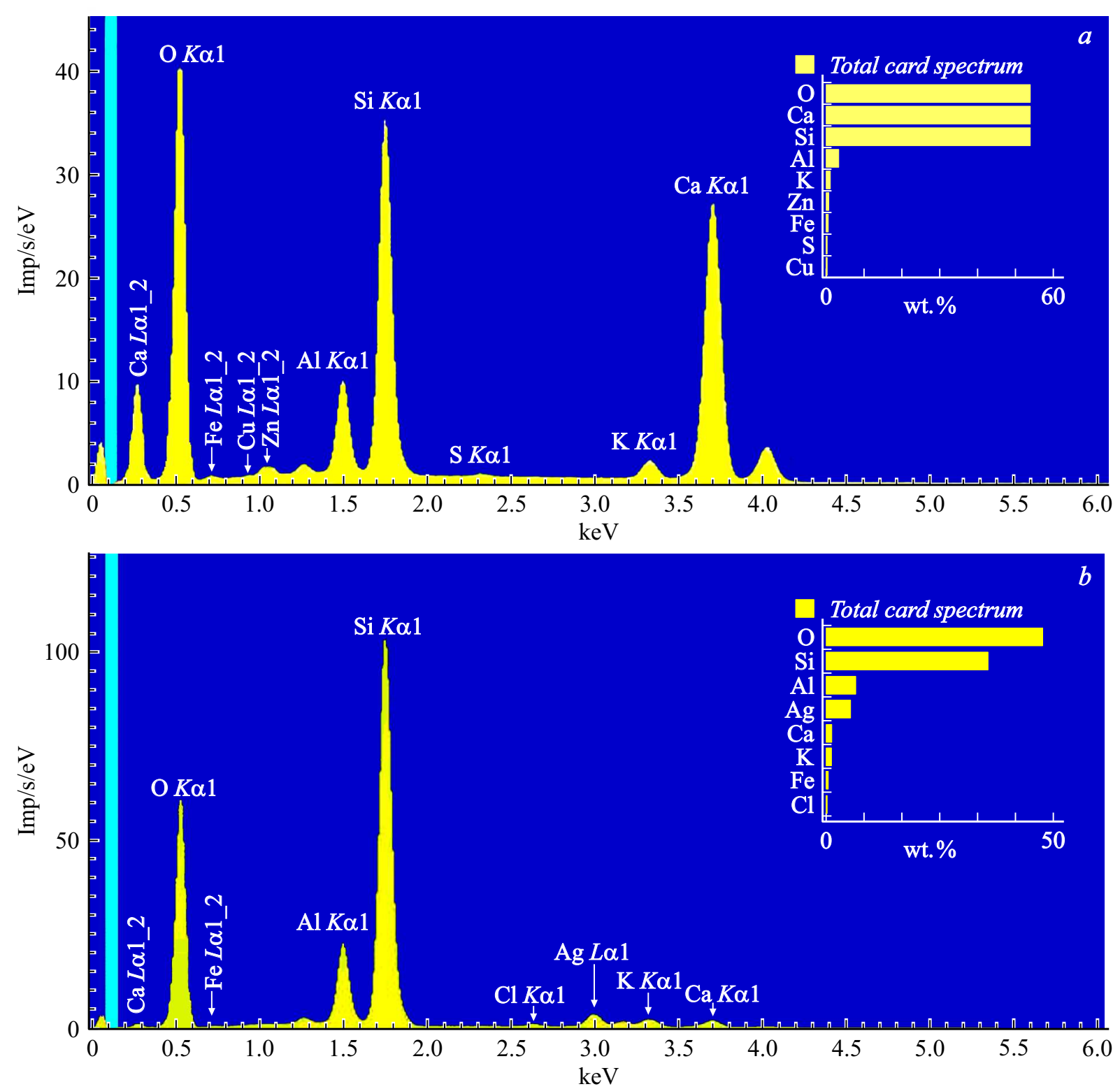

Рис. 1. Спектры характеристического рентгеновского излучения чистого $(a)$ и модифицированного серебром $(b)$ цеолита.

металлического анода. Такое явление возможно лишь в очень сильных $\left(10^{7}-10^{8} \mathrm{~V} / \mathrm{cm}\right)$ электрических полях. Столь сильные поля возникают (кратковременно) на неоднородностях с малым радиусом закругления. В данной системе имеется такой объект.

Отрицательный заряд на поверхности цеолита распределен неоднородно. Он представляет собой отрицательный неподвижный заряд на стенках цеолитовых пор. В глубине пластины этот отрицательный заряд компенсируется положительными зарядами, свободно движущимися в порах цеолита. Поэтому в процессе протекания тока со стороны анода в порах образуется некомпенсированный отрицательный заряд. Этот неподвижный заряд, локализованный (в порах) в местах выхода пор на поверхность цеолитовой пластины, созда- ет поле, способное вызвать ионную полевую эмиссию из анода. Дело в том, что диаметр поры 0.4-0.6 nm, т.е. существенно меньше длины поры (совпадающей с размерами цеолитового кристаллита от 0.5 до $30 \mu \mathrm{m}$ ). Возникающее таким образом локальное электрическое поле на поверхности анода существенно понижает барьер выхода положительного иона из материала анода.

Для объяснения порогового характера наблюдаемого явления будем исходить из простой модели, состоящей из цеолитовой пластины, отделенной зазором от металлического электрода. Проводимость цеолита связана с движением положительных ионов в порах цеолита. Поэтому в процессе протекания тока на поверхности цеолитовой пластины (со стороны анода) образуется неподвижный отрицательный заряд, локализованный на 


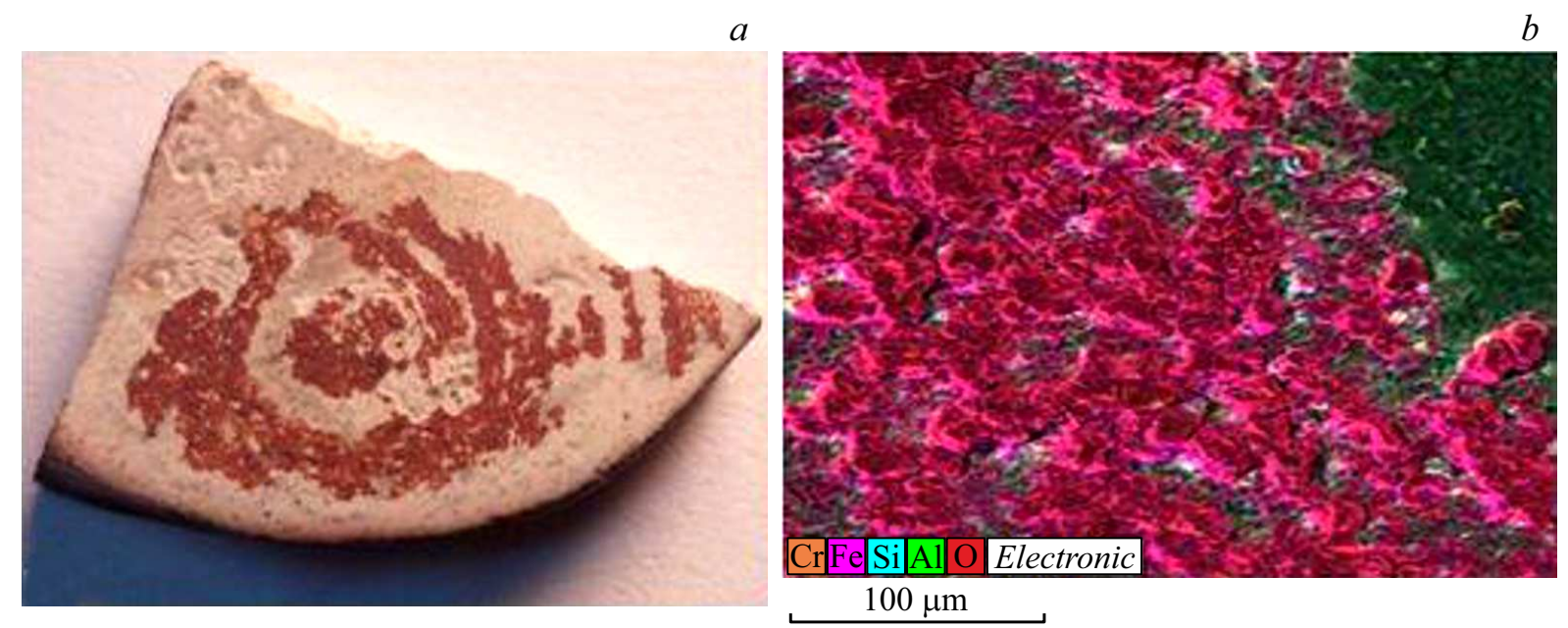

Рис. 2. Фотография поверхности $(a)$ и элементное картирование $(b)$ цеолитовой пластины, модифицированной серебром, после прохождения тока.

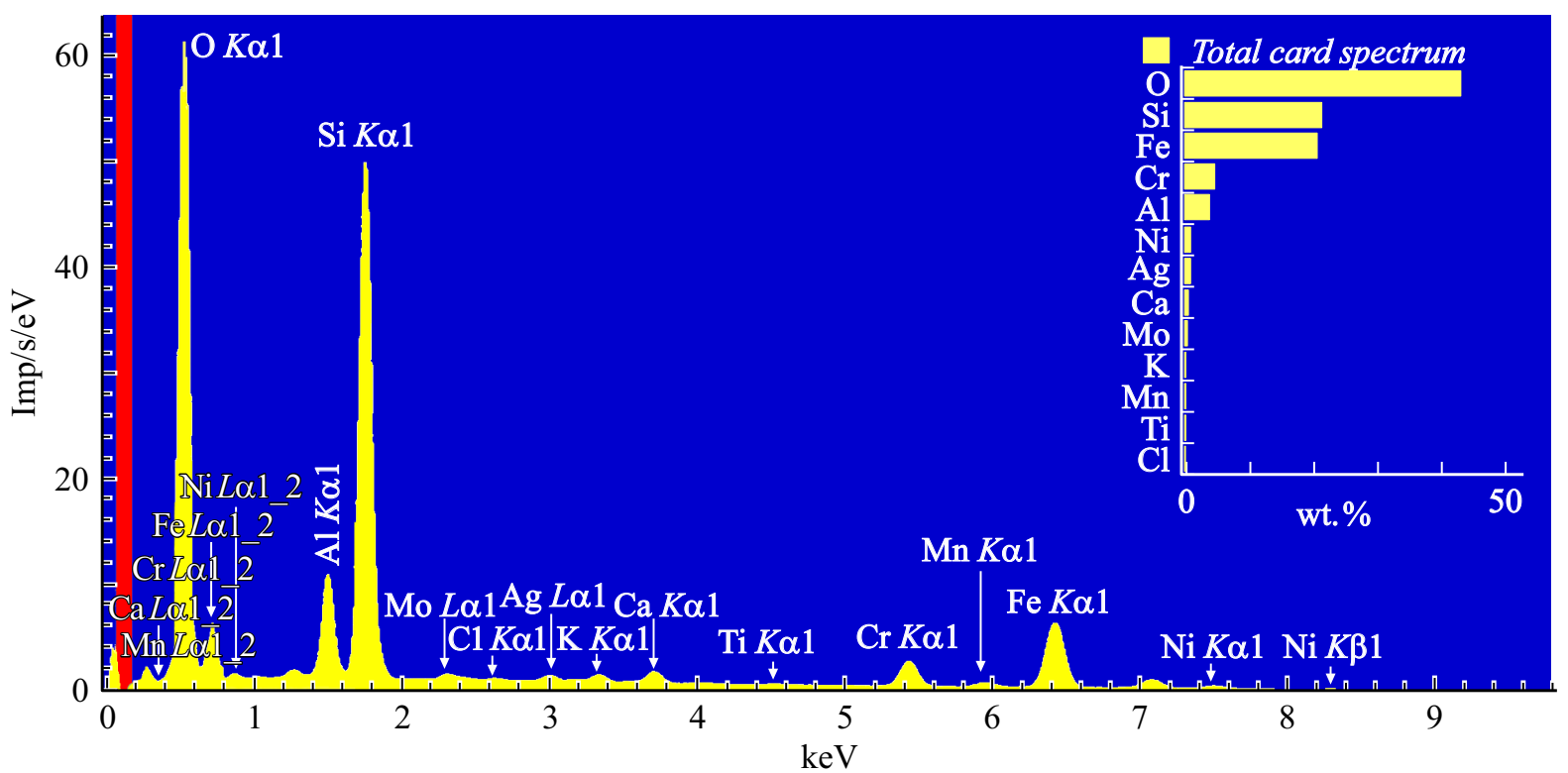

Рис. 3. Спектры характеристического рентгеновского излучения поверхности цеолита, модифицированного серебром, с ионами из анода.

стенках пор, величина которого $q_{0}=J t$. (Здесь $J-$ величина тока, $t$ - время протекания тока.)

При этом на поверхности анода индуцируется точно такой же положительный заряд, реализуемый ионами материала анода. Емкость такого конденсатора $C=\varepsilon_{0} S / d$. (Здесь $S$ - площадь поверхности, $d-$ расстояние между цеолитовой пластиной и электродом.) Разность между энергией связи иона на поверхности анода и энергией связи этого же иона на поверхности цеолитовой пластины обозначим (в электрон-вольтах), как $\Delta$. Целью настоящей работы является изучение устойчивости описанной системы по отношению к переносу части ионов электрода с поверхности анода на поверхность цеолитовой пластины. Обозначим через $q$ величину за- ряда, перенесенного в результате такой неустойчивости с анода на цеолит. Тогда полная энергия нашей системы $W(q)$ имеет вид

$$
W(q)=\frac{\left(-q_{0}+q\right)^{2}}{2 C}+\frac{q \Delta}{e},
$$

где $e=1.6 \cdot 10^{-19}$ - элементарный заряд. Первое слагаемое в (1) - это энергия электрического поля в зазоре, второе - увеличение энергии в связи с переносом части заряда $q$. Отметим, что в связи с этим переносом первое слагаемое уменьшается из-за уменьшения полного заряда $\left(-q_{0}+q\right)$ на противоположных поверхностях. Устойчивое состояние (которое и наблюдается экспериментально) соответствует минимуму полной энергии (1). 
Определяя перенесенный заряд $q$, приравниванием производной от (1) к нулю для массы вещества электрода, перенесенного на поверхность цеолита (с учетом соотношения $\left.M=m_{0} q / e\right)$, получим

$$
M=\frac{m_{0}}{e}\left(J t-\frac{C \Delta}{e}\right),
$$

где $m_{0}$ - масса иона.

Из формулы (2) следует, что масса вещества, перенесенного на цеолит, как функция заряда $q_{0}=J t$ имеет пороговый характер. Если выражение в скобках в (2) отрицательно, то $(M=0)$ массопереноса нет. Когда выражение в скобках становится положительным, имеет место массоперенос. Отметим, что изложенные выше соображения о понижении барьера за счет сильных локальных электрических полей проявляются в уменьшении величины $\Delta$.

\section{Заключение}

Обнаруженный массоперенос со стороны металлического анода на поверхность цеолита указывает на существенно неоднородное распределение электрического поля на контакте пористого ионного материала с металлом (на некоторых участках величина поля достаточна для ионной эмиссии). Объяснение массопереноса основано на понижении энергии связи иона на электроде за счет аномально большого локального электрического поля, созданного неподвижным отрицательным зарядом цеолитовых пор. Показано, что пороговое значение этого заряда, при котором начинается массоперенос, пропорционально емкости зазора между цеолитом и анодом. Рассмотренная в настоящей работе конфигурация не является единственной, в которой проявляются значительные электрические поля. Например, эти поля могут оказать влияние на проводимость цеолитовых порошков и пластин.

\section{Конфликт интересов}

Авторы заявляют, что у них нет конфликта интересов.

\section{Список литературы}

[1] Афросимов В.В., Бер Б.Я., Журихина В.В., Заморянская М.В., Казаниев Д.Ю., Колесникова В.Е., Липовский А.А., Мелехин В.Г., Петров Н.И. // ЖТФ. 2010. Т. 80. Вып. 11. С. 53-61.

[2] Бернацский Д.П., Павлов В.Г. // Письма в ЖТФ. 2014. Т. 40. Вып. 23. С. 104-109.

[3] Гамаюнов Н.И. Процессы переноса энергии и вещества. Тверь: ТГТУ, 2004. 284 с.

[4] Саралидзе 3.К., Голустошвили М.В., Дриаев Д.Г. // ФТТ. 2006. Т. 48. Вып. 7. С. 1229-1230.

[5] Лепезин Г.Г., Хлестов В.В. // Геохимия. 2009. Вып. 3. C. $259-274$.

[6] Kingdona K.H., Langmuir J. // Phys. Rev. 1923. N 21. P. 380.
[7] Ives H. // Phys. Rev. 1923. N 21. P. 385.

[8] Моргулис Н.Д. // ЖЭТФ. 1934. № 4. С. 684.

[9] Добрецов Л.Н. Электронная и ионная эмиссия. М. Л.: ГИТТЛ, 1952. $312 \mathrm{c.}$

[10] Зандберг Э.Я., Ионов Н.И. Поверхностная ионизация. М.: Наука, 1969. 432 с.

[11] Кнатько М.В., Лапушкин М.Н. // ЖТФ. 2013. Т. 83. Вып. 6. C. 51-59.

[12] Muller E.W. // J. Phys. 1937. Vol. 106. P. 132.

[13] Muller E.W. // J. Appl. Phys. 1956. Vol. 27. P. 474.

[14] Muller E.W. // EAY. 1962. LXXVII. Вып. 3. C. 481.

[15] Бернацский Д.П., Власов Ю.А. // ЖТФ. Т. 57. Вып. 11. C. 2257-2261.

[16] Ageev V.N., Bernatskii D.P., Kuznetsov Y.A., Pavlov V.G., Potekhina N.D., Yakshinskii B.V. // Phys. Low.-Din. Struct. 1994. Vol. 7. P. 51-61.

[17] Gollardi G., Galli E. Natural Zeolites. Berlin: SpringerVerlag, 1985. 409

[18] Baerlocher Ch., Meier W.M., Oslon D.H. Atlas of Zeolite Flamework Types. Revised Amsterdam: Elsevier, 2001.

[19] Lebedeva N.N., Orbukh V.I., Sultanov Ch.A. // ЖТФ. 2010. т. 55. Вып. 4. С. 565-568.

[20] Барышников С.В., Ланкин С.В., Стукова Е.В., Юрков В.В. // Современные наукоемкие технологии. 2004. № 6. C. 26-27.

[21] Богомолов В.Н. // УФН. 1978. Т. 124. № 1. С. 171-182.

[22] Kuliyeva T.Z., Lebedeva N.N., Orbukh V.I., Sultanov Ch.A. // Azerbaijan J. Phys. ANAS. 2009. Vol. 15. N 3. C. 43-45.

[23] Соловьев В.Г. // Авт. дисс. СПб. 2005. С. 37.

[24] Kalogeras J.M., Vassilikou-Dova. // Cryst. Res. Technol. 1996. Vol. 31. N 6. P. 693-726.

[25] Orbukh V.I., Lebedeva N.N., Eyvasova G.M., Salamov B.G. // Azerbaijan J. Phys. ANAS. 2015. Vol. 21. N 4. P. 44-46. 